\title{
Multimodal Smart Wheelchair Integrated with Safety Alert System
}

\author{
Harsh Vora, Aime Gupta, Chintan Pamnani, Tushar Jaiswal
}

\begin{abstract}
Elderly and people with disabilities often rely on others for their locomotion. With this emerging world of automation and technologically advanced society we live in a smart wheelchair with appropriate automation can be a life changing innovation for them. One might wonder what is the need for a wheelchair to be smart or for that matter why anything needs to be smart. The answer is simple, to overcome the limitations of the existing technology. We aim on integrating a simple Manually operated wheelchair with features like Obstacle Detection with appropriate technologies such as voice control or gesture control for people who are not able to locomote like a normal person can. With this project, not only do we help a person using a normal wheelchair more easily but also make life easier for those who have other disabilities which are standing as an obstacle making it difficult for them to walk. For instance, a blind person can use a smart wheelchair that allows voicecontrolled movement or even gesture-controlled movement. Another might be of a person who can't speak, will now be able to control everything with his bare hands. Wheelchair coupled with the appropriate sensors that automatically detects the obstacles/objects in the proximity and takes appropriate action consequently and In addition to that it may also be controlled by another person taking care of the disabled by giving commands such as forward, backward, upright etc. This not only reduces the user's efforts but also helps people to take care of their elderly. Voice/gesture control system makes everything simple. Just visualize the application of it in a hospital where the nurse has to manually handle the patient's wheelchair for even the slightest of movement. This system on the other hand needs only text or voice input command, and based upon the predefined command received from the user, the system will execute the task. This project even enforces a GSM module which uses the sim card, which can help in tracking the wheelchair when required, like in case where a user is in difficulty and needs emergency help, a message asking for help can be sent to the intended person.
\end{abstract}

Keywords: Voice control, Hand gesture, Arduino, microcontroller, Bluetooth

\section{INTRODUCTION}

The wheelchair is one of the most usually utilized assistive devices for improving and empowering the

Revised Manuscript Received on April 17, 2020.

* Correspondence Author

Harsh Vora*, Computer Science spec. Information Security, Vellore Institute of Technology, Vellore, India. Email: harsh.vora1753@gmail.com

Aime Gupta, Computer Science, Vellore Institute of Technology, Vellore, India.Email:aimegupta@gmail.com

Pamnani Chintan Rajesh, Computer Science, Vellore Institute of Technology, Vellore, India.Email: chintanpamnani000@gmail.com

Tushar Jaiswal, Computer Science, Vellore Institute of Technology, Vellore, India. Email: tusharj045@gmail.com

(C) The Authors. Published by Blue Eyes Intelligence Engineering and Sciences Publication (BEIESP). This is an open access article under the CC BY-NC-ND license (http://creativecommons.org/licenses/by-nc-nd/4.0/) individual versatility of the individuals experiencing issues in walking.A brilliant wheelchair is likewise not another idea today. There are numerous researches going on to increase the efficiency and features of the wheelchair. Smart Wheelchair is the term commonly used to define a device that integrates technology and services through networking to enhance power efficiency and improve the quality of living. Today the manual wheelchair either requires a handler (or partner) to push the wheelchair from behind to move or it might have the peddle near the wheels to move the wheelchair. In any case, the savvy wheelchair is outfitted with the highlights that make the mobility of the wheelchair far simpler than the manual ones. The smart wheelchair can be controlled with the motions so the individual could without much of a stretch move hands to make the wheelchair move[1][2], it can likewise be constrained by voice orders[3][4]. This easy mobility opens up opportunities for wheelchair users to study, work and engage in social and cultural activities. When smart is equipped with safety then it becomes really smart as this wheelchair has a safety module that sends a prompt to the precious ones of the proprietor of the wheelchair when the individual tumbles from the chair or is met with a mishap[13]. For many people, this appropriately designed wheelchair is the first step towards inclusion and participation in society.

\section{OBJECTIVES}

- Designing and building a Smart Electric Wheelchair System that is not controlled by the use of hand movements, voice commands. The outcome of this project will facilitate the mobility of people with disabilities. It can be used well with little effort by these people to be able to use it.

- Motion body gestures will be added using the accelerometer module to control the wheelchair using gestures[1][2].

- The voice command feature will be using the Bluetooth module and will control the wheelchair with voice commands[3][4].

- Detection of the obstacle will be performed using ultrasonic sensors[9].

- This integrated model is a complete package for people with physical disabilities[6].

- Objective is to minimize the daily workload through automation.

- Implementing GSM model aims to promote simplicity in operating our smart wheelchair.

- The system which is controlled by GSM will

Published By:

Blue Eyes Intelligence Engineering

\& Sciences Publication

DOI: 10.35940/ijeat.D8423.049420

Journal Website: www.ijeat.org 
utilize the use of text messages through the user's smartphones.

- GSM models help to get rid of managing small jobs that we do every day manually.

- It acts as a helping hand for the disabled people, old aged people who are not able to do their tasks by themselves.

- We are implementing this technology so that the users are able to control their smart wheelchair even when they are not near to it, effectively.

- GSM Module is used to send an emergency alert to a user's relative regarding any error or dysfunction of the wheelchair so that the safety of the user is ensured.[13]

\section{PROJECT PLAN}

\section{A.Timeline And Gantt Chart}

OBSTACLE DETECTION-20th Dec,2019-07th Jan,2020

HAND GESTURE-10th Jan,2020-10th Feb,2020

VOICE CONTROL-11th Feb,2020-01st March ,2020

GSM Module- 2nd March,2020- 14th March,2020

Documentation- 20th Dec,2019-2nd April,2020

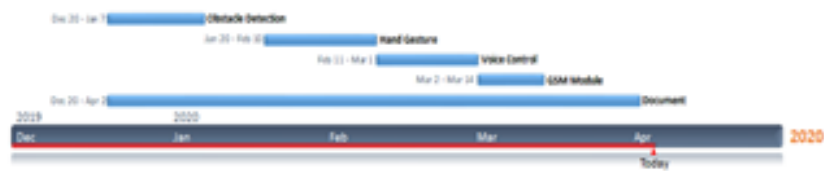

\section{PROPOSED METHODOLOGY}

\section{A. System Layout (Obstacle Detection)}

WHENEVER THE MOVING WHEELCHAIR COMES IN PROXIMITY OF ANY OBJECT (DISTANCE LESS THAN 30 CM.) THEN THE ULTRASONIC SENSOR WHICH IS CONTINUOUSLY READING THE DISTANCE OF THE SURROUNDINGS NEAR THE WHEELCHAIR SENDS THE MOTOR DRIVER SIGNAL TO SET BOTH THE WHEELS ON LOW.

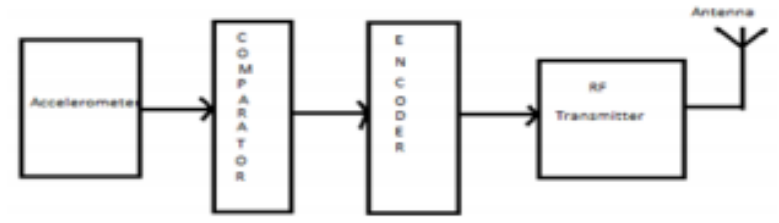

Transmitter module

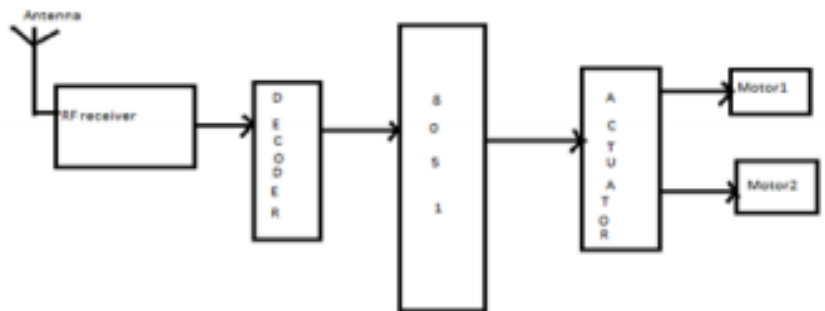

Receiver module

\section{B. System Layout (Hand Gesture)}

This small piece could be attached to the gloves which could be worn by the person using the wheelchair. The accelerometer could be rotated about the three orthogonal axes. Different orientations could be achieved by using these axises. So based on the rotation and gestures along these axes allow the motion of the wheelchair in the particular direction.

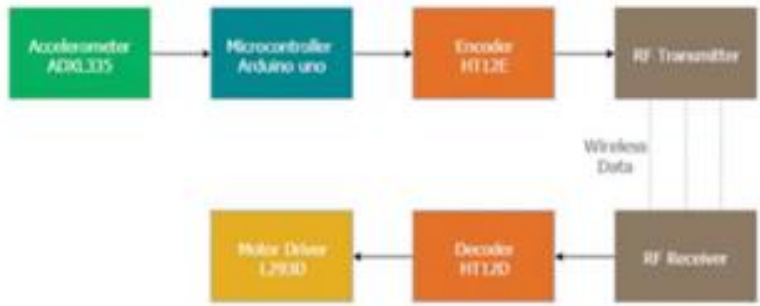

\section{System Layout(GSM Module \& Arduino Interfacing)}

GSM Module is basically like a modem. It is connected to an arduino or other microcontroller for output. Whenever the person sitting on the wheelchair falls or meets with an accident this module sends alert notification to the near and dear ones.

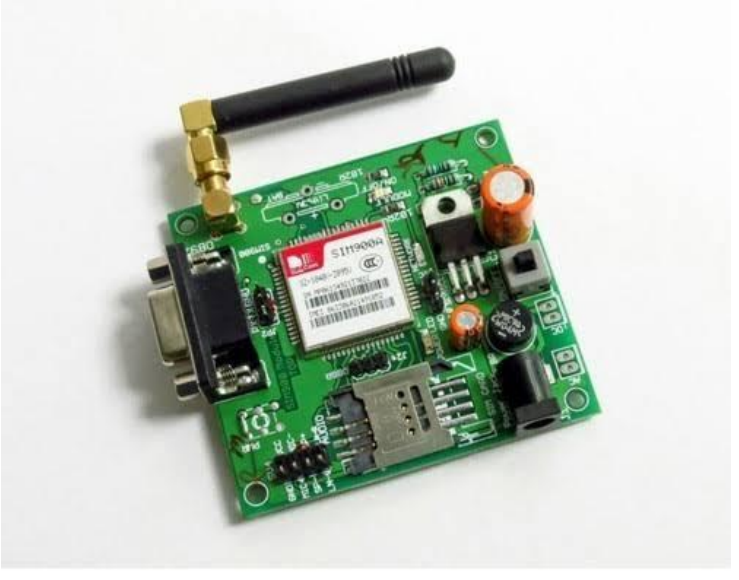

D. Block Diagram(Obstacle Detection)

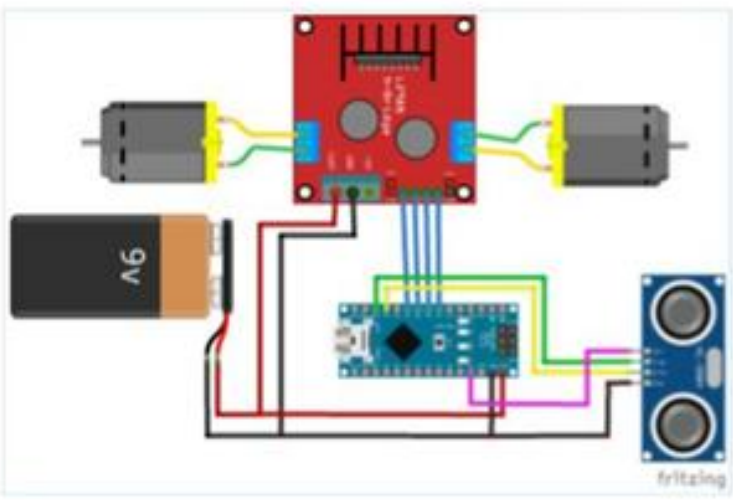

E. Block Diagram (Hand Gesture)

Published By:

Blue Eyes Intelligence Engineering \& Sciences Publication 


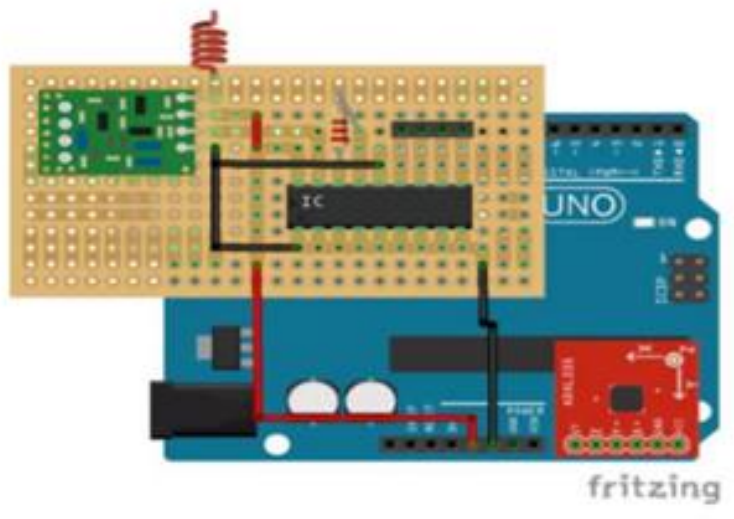

\section{F. Block Diagram (Voice Control)}

The implementation of wireless motion control of the wheelchair using voice was done with the help of HC- 05 module. The commands were spoken on the intermediary app which converts each command such as forward, stop, backward to a character and then the character is sent. The arduino acts according to the character received which results in the motion of the arduino.

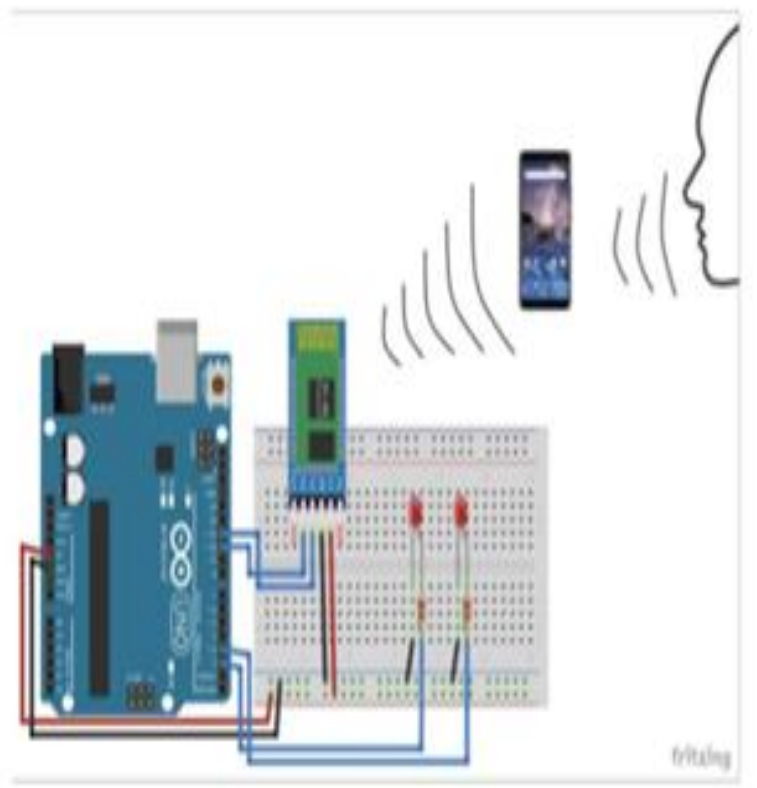

\section{G. Block Diagram(GSM Module \& Arduino Interfacing)}

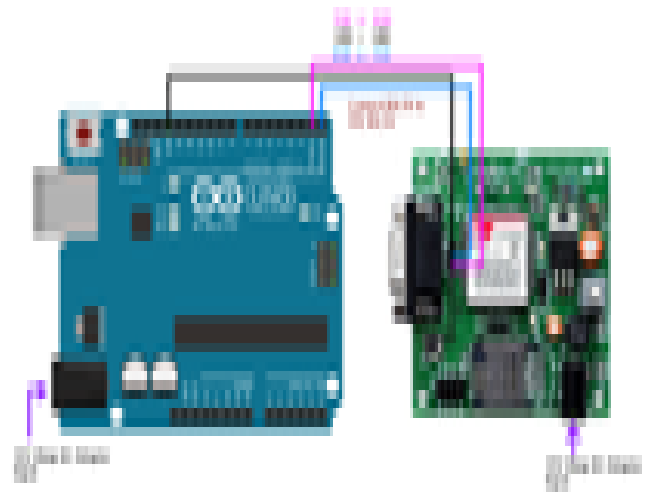

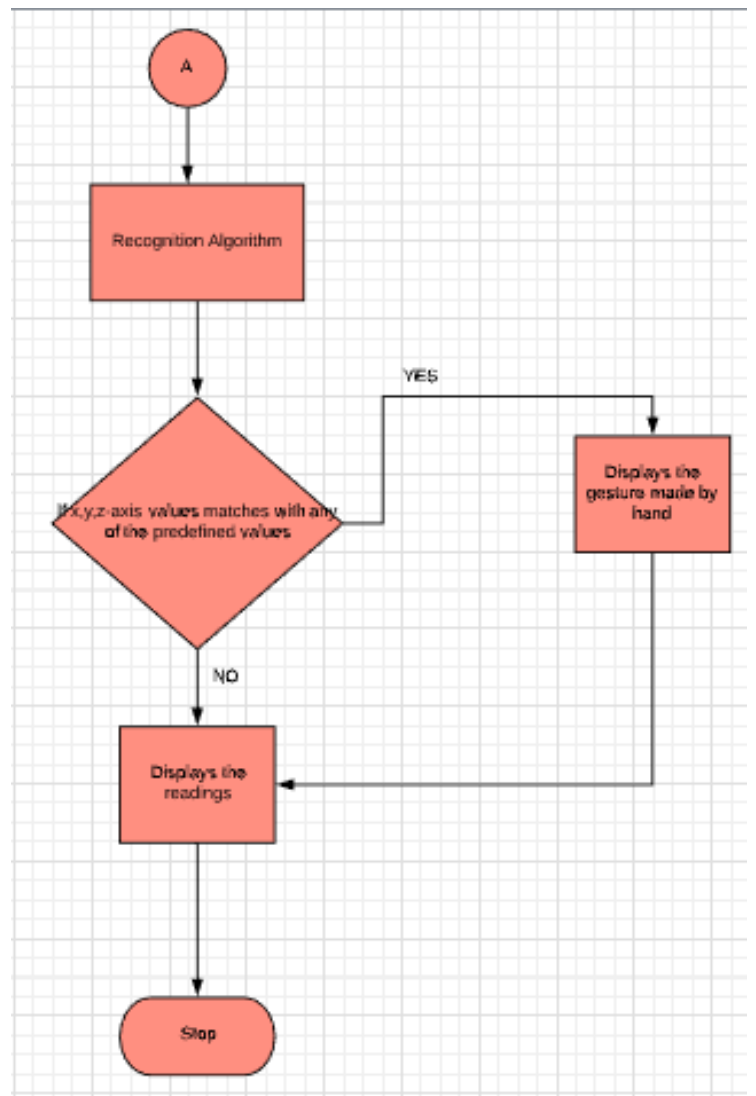

V. OVERVIEW

H. Hand Gesture Recognition System

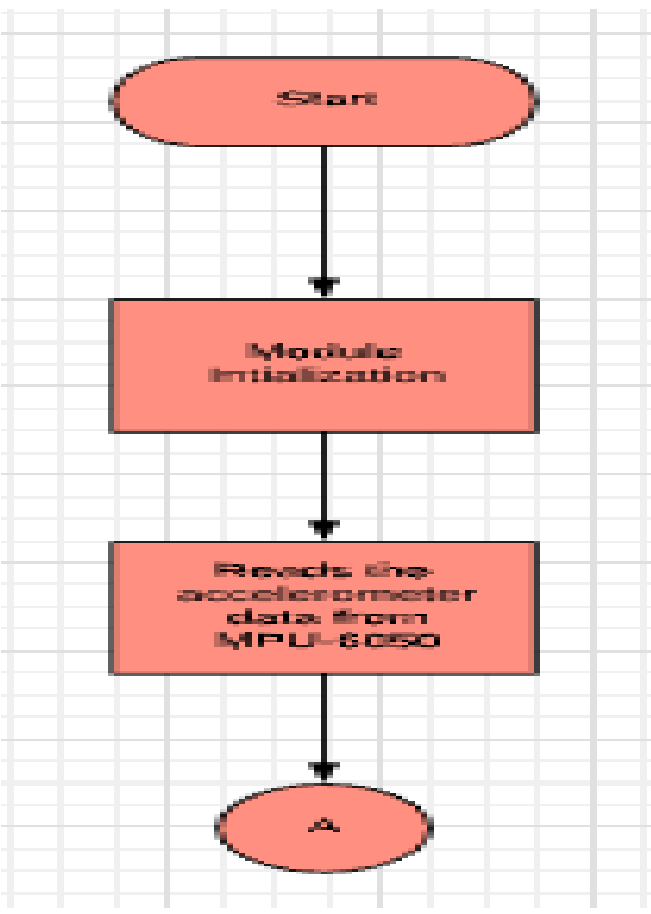

Published By:

Blue Eyes Intelligence Engineering

\& Sciences Publication

(C) Copyright: All rights reserved. 


\section{Voice Control}

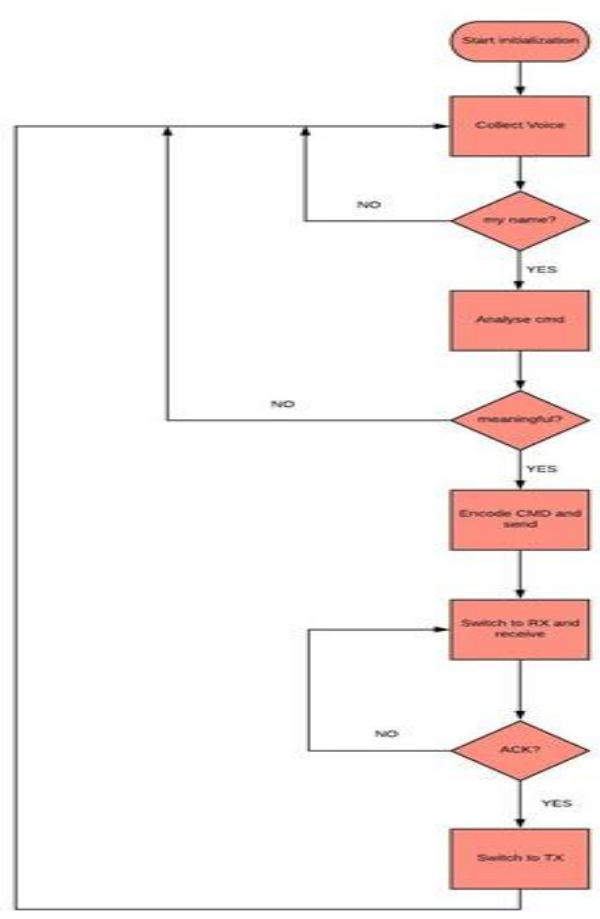

\section{J. Obstacle Detection}

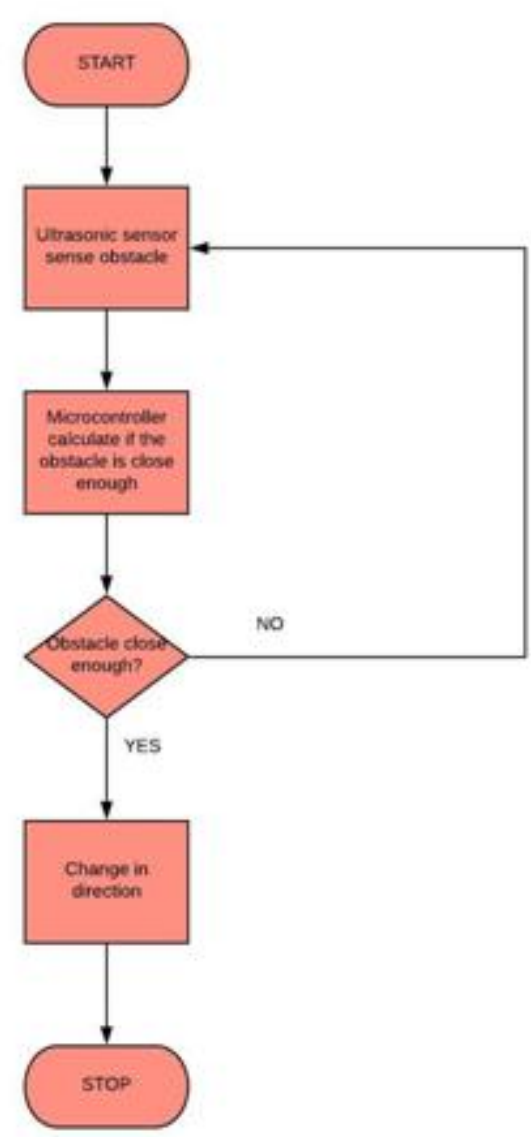

\section{K. PIN Description}

Vcc 5 volt supply must be connected to this pin.

X-OUT: This pin provides Analog output in X-motion

Y-OUT: This pin assigns Analog output to the $y$ direction

Z-OUT: This pin provides Analog output in the zdirection
GND: Ground

ST: This pin was used to set the sensor sensitivity

SIM800A Module: To control the appliances via text messages

Active SIM card: To be used in GSM Module

Relay module: To control the appliances

Power adapter: To power the model components

Jumper wires: To establish connections between Arduino, relay and GSM modules.[18]

Motor and Fan: Sample appliance

Power Bank: To supply DC current
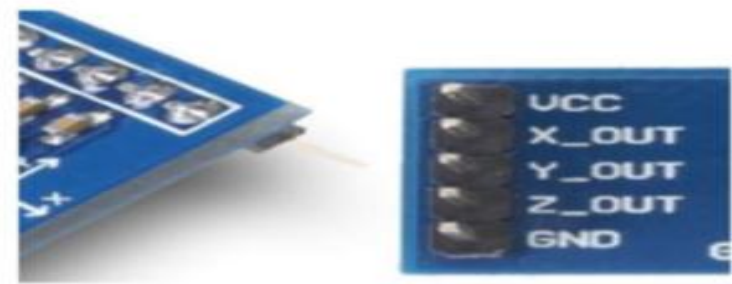

\section{WORKING}

- Our Smart Wheelchair is a discreet tool that can feel self-control in front of it and avoid them turning in the opposite direction. This design allows the robot to wander into unknown space by avoiding collisions, which is a key requirement of any autonomous robot.

- Use of the Obstacle Avoiding the robot is not limited to and is used in many military organizations now helping to perform many dangerous tasks that other soldiers cannot do. Here the Ultrasonic sensor is used to detect obstacles in the path by calculating the distance between the robot and the obstacle. When a robot detects any obstacle it changes its path and keeps moving. The basic premise of ultrasonic sensor operation is to pay attention to the time taken by the sensor to transmit ultrasonic beams and to receive ultrasonic beams after hitting the surface.[12]

- The user can enter different commands to move in a wheelchair like $\mathrm{F}$ forwards, B for back, S for standing and so on.

- When these commands are entered, the transmitter transmits the signal through the HT12E encoder received by the robot that finally receives the HT12D decoder. After this cycle, the wheelchair begins to move and stop in front of any obstacle using ultrasonic sensors.

- Here the accelerometer reads the $X$ YZ coordinates when performing a hand gesture and sends the $\mathrm{X} \mathrm{YZ}$ coordinates to the Arduino (here we do not need the $\mathrm{Z}$ axis that requires only two $\mathrm{X}$ coordinates. The Arduino checks the corresponding values and sends code 4 Encoder IC.

- Encoder transmits data to an RF transmitter and transmits data received by the RF transmitter. The receiver sends 4 codes to the Decoder IC and the decoder transmits it to the motor Driver IC. Later the car driver made the decision to turn both motors to where they were needed.

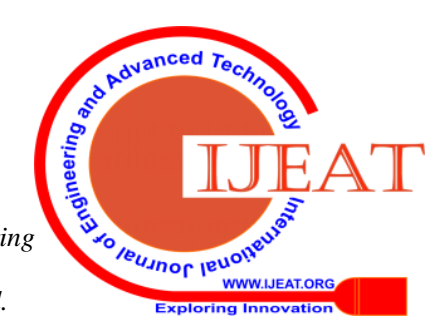


- Another thing we will add is voice management. The Bluetooth HC-05 module is connected to the arduino using the TX and RX pins.

- The transmitter sends the signal and waits for the receiver to receive the signal back. Bluetooth is scanned and paired using a mobile phone.

- And through an app called "Bluetooth Voice" voice messages are sent to the arduino that works according to the received messages. Voice messages are modulated in other characters that are sent via bluetooth to arduino. After that with the letters received the arduino takes action.

- For GSM to work, we will use the smart phone to connect with our load or devices through blue-tooth.

- After making the necessary connections, we will start the android application supported by Bluetooth service so as to convert the voice of the user into the string, which will be sent to the Bluetooth module installed with our automation system.

- $\quad$ Then the Bluetooth module will compare the received string with some of the predefined strings.

- If any of the string matching takes place, then corresponding action will be executed by the wheel chair system.

\section{NOVELTY OF PROJECT}

The percentage of people with disabilities has increased in rural and urban parts of India. Disability may occur as a result of birth or due to some medical or accidental cause. The purpose of making a smart wheelchair is using an ultrasonic sensor to help physically handicapped people move from one place to another without colliding with any obstacles. Today, in India, many people suffer from disability; there are people in the lower half of the body paralyzed. This wheelchair will add comfort and make people's lives easier.

Benefits for people who:

- Disabled person.

- Those who crawl.

- Those who walk with the help of a stick.

- Those have serious and chronic joint / tissue problems.

- Those with stiffness in movement or who have mobility, voluntary movement or tremor or have weak bones.

- Those who have difficulty in connecting motor cells with neurons.

- Those who have lost their senses in the lower part of the body due to disability or other problems.

- Those who have twisted limbs and suffer from any type of physical injury.

\section{IMPROVEMENTS FROM EXISTING SOLUTIONS}

There are many products in the market that offer safety to aged or disabled. With the help of technology, the medical sciences have advanced remarkably. Everything is being added with the prefix "smart". There are smart watches, TVs, boards. Similarly, there are smart wheelchairs too. But these designs can be optimized, can be hybridized with multiple technologies like hand gesture control, voice control, etc.We aim on achieving a much simpler yet efficient prototype of smart wheelchair with voice control and hand gesture control technologies.

\section{FUTURE SCOPE}

In future this smart wheelchair can be equipped with mind control technologies. We'll be able to detect the brain cells using a sensor and the smart wheelchair will move in that path. The user does not have to do anything. Only a brain sensor will be attached to the user and the wheel chair will automatically move and it'll also detect obstacles and warn the user about it.

\section{RESULT AND ANALYSIS}

\section{a) Obstacle Detection}

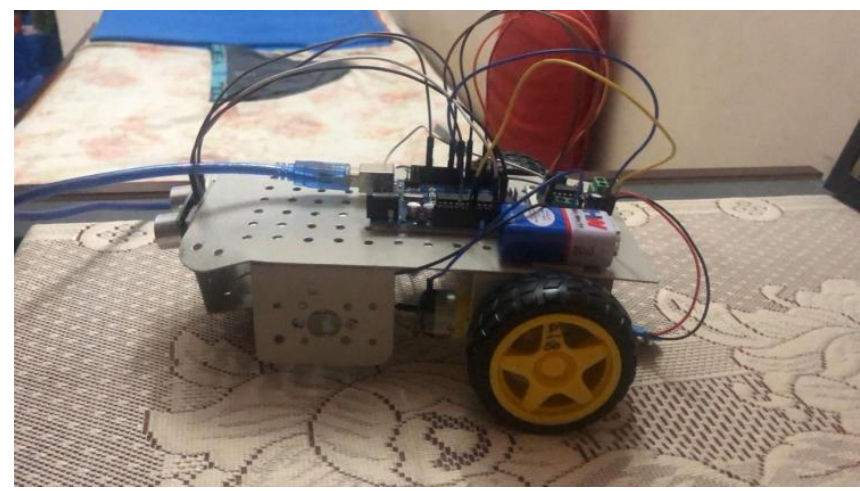

The System can detect any obstacle upto a defined range successfully and stops.

\section{b) Hand Gesture}

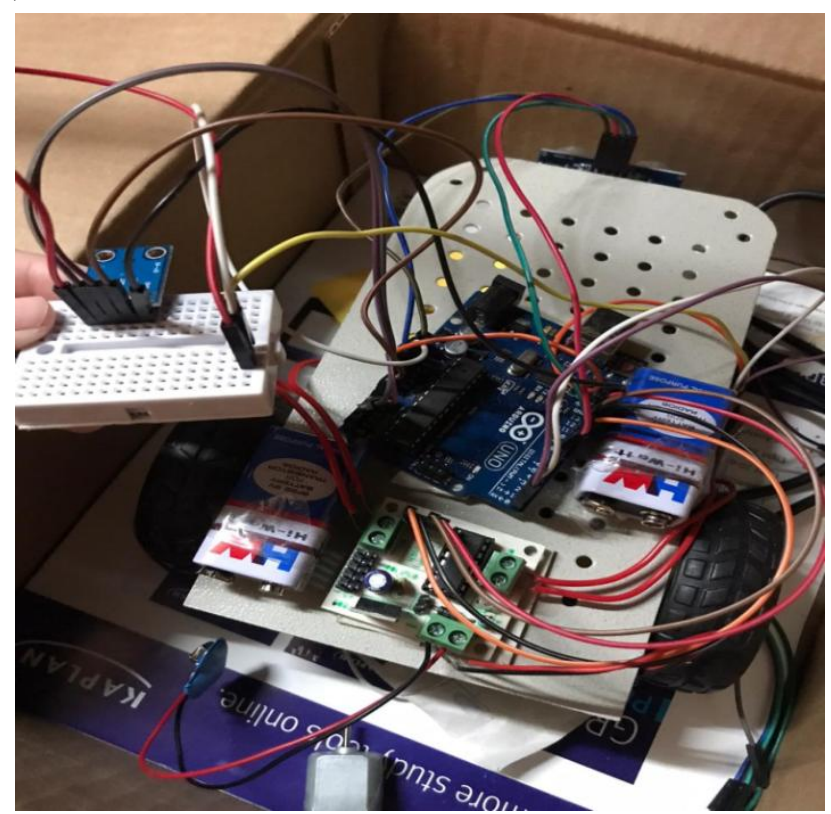

Fig 1: Hand Gesture

In Fig 1 ,as shown above, a person can calibrate gestures of his own choice and make the system move in that direction. After calibrating(user-defined) the accelerometer sensor on the palm the results were as follows :

\begin{tabular}{|l|l|}
\hline Action & Direction \\
\hline Tilt forward & Moves forward \\
\hline
\end{tabular}

Published By:

Blue Eyes Intelligence Engineering

\& Sciences Publication

(C) Copyright: All rights reserved.

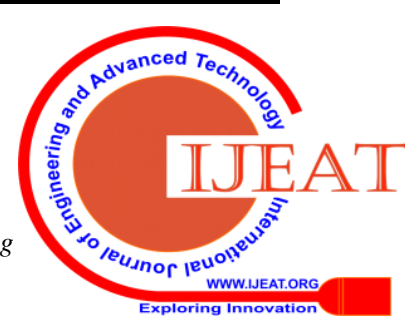




\begin{tabular}{|l|l|}
\hline Tilt backwards & Moves backwards \\
\hline Tilt right & Directed towards right \\
\hline Tilt left & Directed towards left \\
\hline Keep straight & Stop \\
\hline
\end{tabular}

\section{c) GSM Module}

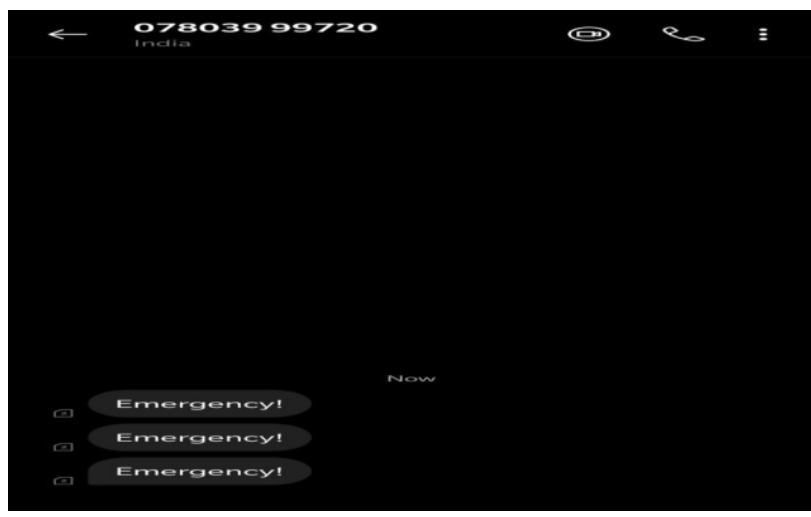

Fig 2: GSM Module

In Fig 2, as shown above, whenever there is a security alert,the GSM module will send a message to the person's near ones. The message is sent successfully if it finds any obstacle near the wheelchair.

\section{d) Voice Control}

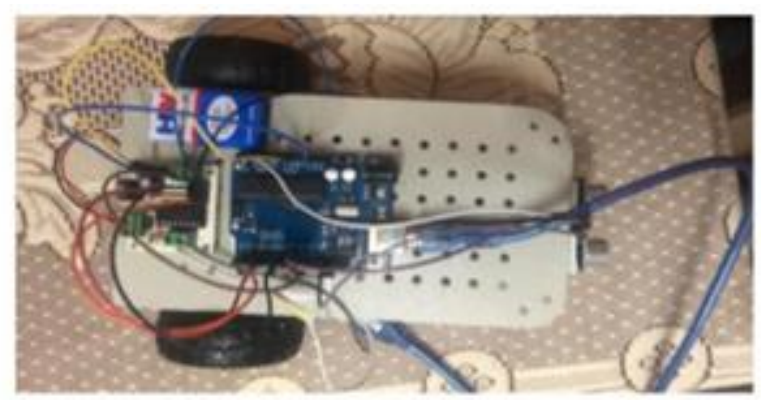

Fig 3: Voice Control

In Fig 3, as shown above, the user can control the wheelchair using his voice, he can tell the commands and the wheelchair will move accordingly. He can also put brakes.

The result are as follows:

\begin{tabular}{|l|l|l|}
\hline S.No & Speech & $\begin{array}{l}\text { Character } \\
\text { Sent }\end{array}$ \\
\hline 1 & Forward & "F" \\
\hline 2 & Backward & "B" \\
\hline 3 & Stop & "S" \\
\hline 4 & Left & "L" \\
\hline 5 & Right & "R" \\
\hline
\end{tabular}

\section{CONCLUSION}

There has been a remarkable growth and enhancement in the sensor technology available to us. With the help of these advanced technologies, in this project we aimed at development of a prototype for a Smart wheelchair which can be utilized by people with different disabilities independent of their disability type. We designed and tested a prototype of a smart wheelchair with multiple operating modes which can be toggled using a switch as per user requirement. The hand gesture control mode allows the user to control the wheelchair with the help of the movement of the hand captured by the accelerometer. On the other hand, the user can even use voice control mode which takes the user's commands as input and performs the desired action. The model works effectively well with its obstacle detection capabilities achieved by using ultrasonic sensors. In addition to this, the GSM module makes it possible to ensure the user safety and emergency control. An alert will be sent immediately to the cell phone of the guardian of the user or medical support to respond within seconds in a situation of emergency.

\section{REFERENCES}

1. Shaari, A. R., Jani, M. \&. M., \& Yunus, A. S. M. (2017). A Smart Wheelchair Prototype Based On Hand Gesture Control. Journal of Engineering and Science Research, 1(2).

2. Lodh, A., Ghosh, D., \& Ghosh, D. (2018). Accelerometer and Arduino Based Gesture Controlled Robocar. International Journal of Innovative Research in Science, Engineering and Technology, 7(8), $1-8$

3. Meena, K., Gupta, S., \& Khare, V. (2017). Voice controlled wheelchair. International Journal of Electronics, Electrical and Computational System, 6(4), 23-27.

4. Chauhan, R., Jain, Y., Agarwal, H., \& Patil, A. (2016, January) Study of Implementation of voice controlled wheelchair. In 2016 3Rd International Conference On Advanced Computing And Communication Systems (ICACCS) (Vol. 1, pp. 1-4). IEEE

5. Pahuja, R., \& Kumar, N. (2014). Android mobile phone controlled bluetooth robot using 8051 microcontroller. International Journal of Scientific Engineering and Research, 2(7), 14-17.

6. A. Mishra, P. Makula, A. Kumar, K. Karan and V. K. Mittal, "Multimodal controls of a smart robot," 2015 Annual IEEE India Conference (INDICON), New Delhi, 2015, pp. 1-6.

7. .Megalingam, R. K., Sreekanth, S., Govardhan, A., Teja, C. R., \& Raj, A. (2017, January). Wireless gesture controlled wheelchair In 2017 4th International Conference on Advanced Computing and Communication Systems (ICACCS) (pp. 1-5). IEEE.

8. Rabhi, Y., Mrabet, M., \& Fnaiech, F. (2018). Intelligent contro wheelchair using a new visual joystick. Journal of healthcare engineering, 2018.

9. Arun Francis G, Arulselvan M, Elangkumaran P, Keerthivarman S, Vijaya Kumar J. Object Detection Using Ultrasonic Sensor International Journal of Innovative Technology and Exploring Engineering (IJITEE), Volume-8 Issue-6S, April 2019

10. R,M.Madane (2015). Gesture Control Wireless Wheelchair Prototype. International Journal of Engineering Research \& Technology, 4(4), 1-4

11. Mohamed Abd El-Latif Moawad, Ahmed Fathy, Ahmed Hafez "Smart Home Automated Control System Using Android Application and Microcontroller" International Journal of Scientific \& Engineering Research, Volume 5, Issue 5, May2014 ISSN 22295518

12. Girish M. (2016, November 26). Hand Gesture Controlled Robot Retrieved January 5, 2020, from https://create.arduino.cc/projecthub/mayooghgirish/hand-gesturecontrolled-robot-4d7587

13. Jojo (2016),.How to Interface GSM Module to Arduino-Send and Receive SMS. . Retrieved 2020, from .

Published By:

Blue Eyes Intelligence Engineering \& Sciences Publication

(C) Copyright: All rights reserved.

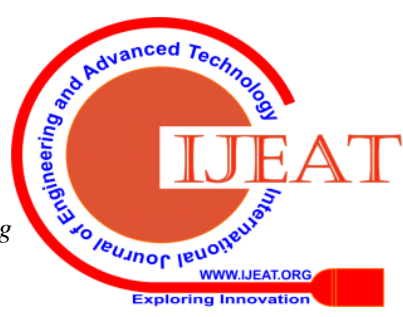


14. http://www.circuitstoday.com/interface-gsm-module-with-arduino

15. Santos, R. (2016). Guide for Relay Module with Arduino. Retrieved 2020,from https://randomnerdtutorials.com/guide-for-relay-modulewith-arduino/

\section{AUTHORS PROFILE}

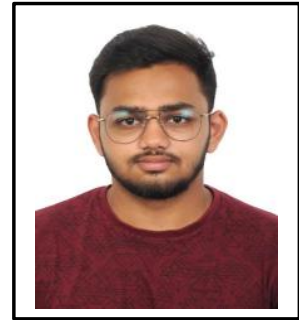

Harsh Vora is a third-year student currently pursuing his BTech. in Computer Science with Specialization in Information Security at Vellore Institute of technology, Vellore, India. Being an Information security enthusiast he has notably worked on projects in the field of Cybersecurity and Cryptography. He worked as a software engineering summer intern at Kalki Tech. and was mentored by industry specialists to complete a software project for a duration of six weeks. He was a former technical and management core member of the International Society of Automation, VIT(ISA-VIT). His team worked on numerous IOT and Automation based projects. He was a part of many Technical events during his time in ISA-VIT.

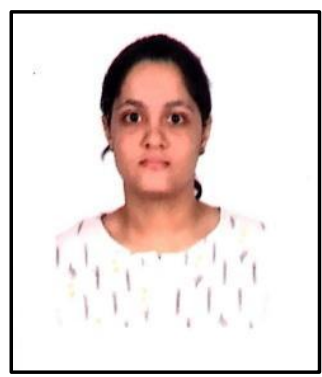

Aime Gupta is a third-year student currently pursuing his BTech in core Computer Science at Vellore Institute of Technology,Vellore,India.She has earned NPTEL certificates on Data Structures and Database Management. She is database management enthusiast and has several projects under this domain.She has worked as UI developer at VSOFT Technology as a summer intern for six weeks.She has made interactive pages using BootStrap. She has developed an interactive UI using AngularJS and was mentored by industry experts.She has high proficiency for Web Development and has decent knowledge on Data Structures.She was the former management head for Startups Club and has been to Bangalore for managing an event where she had met Startup owners .She was part of many management events during her time in Startup's Club.

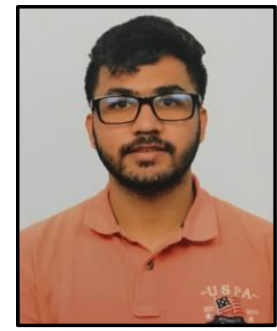

Pamnani Chintan Rajesh is a third-year student currently pursuing his Btech in core Computer Science at Vellore Institute of Technology, Vellore, India. He has decent knowledge in search optimisation using ElasticSearch and has worked as an intern at Reliance, Jio industry for the same under the Vice President of Reliance for almost 2 months. He has a decent knowledge in subjects like Data Structures and Algorithms, Internet of things (IOT) . He is currently into internship cum training under the professors of IIT kanpur. He has worked on several projects on Web Development, Operating Systems. He was also a part of several NGOs as a fundraiser.

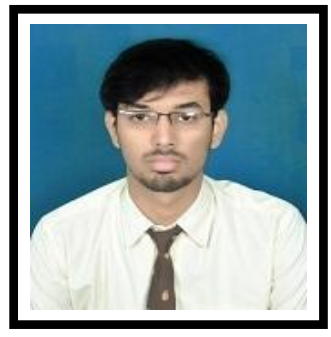

Tushar Jaiswal is a third-year student currently pursuing B-Tech in Compute Science and Engineering at Vellore Institute of Technology, Vellore, India. He is a person with good academic history and a decent knowledge in the field of Internet of Things (IOT), Web Development and Application Development in Android and high proficiency and interest in the fields of Data Structure and Algorithms. He has worked with Hindalco Industries which comes under the Aditya Birla group as an intern. 